\title{
Knowledge Workers and their Role in Building Strategic Capabilities" Analytical Research in the Faculties of University of Salaheddin / Erbil
}

\author{
Hadeel Kadhim Saeed ${ }^{1}$, Baraa Shawqi Al-Ani ${ }^{2}$ \\ ${ }^{1,2}$ Department of Public Administration. College of Administration and Economics. University of Baghdad, Al Wazeria. Baghdad. Iraq
}

\begin{abstract}
The current paper (research) is an attempt to focus the light on the role of knowledge workers (a statistically significant variable of influence) in building the strategic capabilities (as a responsive variable) and finding out about the reality of adopting these two concepts by the faculties of University of Salahaddin /Erbil in order to test both the correlation and the effect of those concepts as well as the existence or the non-existence of any statistically significant differences among the variables used in the research so that to be able to suggest a number of recommendations helpful in building strategic capabilities beneficial for the researched university. The point in conducting the research was to inspect the availability of knowledge workers dimensions and the role of those dimensions in building the desired strategic capabilities. The analytical descriptive method was used in conducting this paper which also focused on the academic leaderships of University of Salahaddin / Erbil (106 faculty members) including Deans, Assistant Deans and Heads of Faculties. Samples were collected from 97 participants (respondents) so that the research was able to reach a number of conclusions on top of which was the existence of statistically significant correlation between knowledge workers and strategic capabilities in addition to the moral influence of knowledge workers in building strategic capabilities which, in part, indicated that knowledge workers had enough intellectual and mental qualifications enabling them to be regarded as an essential resource to be used in building strategic capabilities. On top of the recommendations suggested was to provide an organizational environment to assist in nurturing and developing mindsets so that to support the role of knowledge workers, as well as to revise the financial incentives and honorary rewards currently adopted by the researched faculties
\end{abstract}

Keywords: Strategic Capabilities, Knowledge Workers

\section{Introduction}

Educational institutions reflect the cultural, intellectual, social and scientific statuses of the societies in which they exist. Being so attached to their societies, they scientifically, intellectually and socially work as centers for developments in addition to their socially unique responsibilities being the base for any revival to take place. This is why the education institutions are always competing with one another to be the pioneer in having their human resources acquiring uniquely distinctive expertise and scientific qualifications that enable them to excel in the use of their profound knowledge, and thus directing that knowledge towards building the strategic capabilities of their institutions. Being as such, the current paper is aimed at those who have and employ knowledge in dealing with the requirements of the century. A knowledge worker is accordingly one of the main pillars used in the overall development (of a nation) in all its dimensions (political, economic and social alike) since they (knowledge workers) act as an essential source used for managing and directing the resources of the educational institutions. For it is through their experiences, knowledge and analytical capabilities that they are capable of confronting challenges only the creative and the scientifically and intellectually qualified can, and in being so, they (knowledge workers), play a vital role in building the strategic capabilities of the institutions they work for. Therefore, once the Iraqi educational institutions understand the importance of having knowledge workers, and start taking advantage of their presence through providing encouraging environment appropriate for creativity, they will be ensuring their future by acquiring strategic capabilities vital in narrowing the intellectual gap existing between the Iraqi educational institutions and their counterparts worldwide. Being the largest university in Iraqi Kurdistan, the University of Salahaddin with its (14) faculties was chosen as the field where the research was to be conducted especially that the university has been scientifically and intellectually enriching the Iraqi society and is therefore widely regarded as a fountainhead of intellectual interest.

The paper is divided into four chapters: the first one dealing with the methods involved, the second with the theoretical framework(s), the third with the scientific side and the fourth with the conclusions, recommendations, and suggestions.

\section{Review of References}

In their focus on knowledge workers, and in devising the best ways to acquire them and invest in their various capabilities, researchers have been disagreeing with one another in their opinions and previews on how to embody the concept of knowledge workers following certain intellectual and philosophical views which reflected their assessment of this elite (knowledge workers). Table (2) shows differences among those views. 


\section{International Journal of Science and Research (IJSR) \\ ISSN (Online): 2319-7064}

Index Copernicus Value (2016): 79.57 | Impact Factor (2015): 6.391

Table 2: Views of some writers on the concept of knowledge workers

\begin{tabular}{|c|c|c|}
\hline Definition & $\begin{array}{c}\text { Researcher } \\
\text { and Yeaar }\end{array}$ & Ref. \\
\hline $\begin{array}{c}\text { Highly experienced and highly educated people } \\
\text { whose main purposes of their works include } \\
\text { creating, distributing and applying knowledge. }\end{array}$ & {$[1]$} & \\
\hline $\begin{array}{c}\text { Workers who have special intellectual means for } \\
\text { producing goods and services and who work on } \\
\text { enhancing their own knowledge which managers } \\
\text { in their organizations lack. One example is the } \\
\text { gained info about customers. Those workers have } \\
\text { also the chance to put the organizations to tests, }\end{array}$ & & \\
$\begin{array}{c}\text { and in doing so adding competitive characteristics } \\
\text { ind }\end{array}$ & & \\
\hline $\begin{array}{c}\text { A bunch of individuals who excel in using } \\
\text { observations and concepts depending on }\end{array}$ & [3] & \\
$\begin{array}{c}\text { information and knowledge available in order to } \\
\text { create wealth, adding extra values for products } \\
\text { through their creativities, analytical abilities, } \\
\text { evaluations and designs. }\end{array}$ & & \\
\hline $\begin{array}{c}\text { Individuals who understand their jobs, the } \\
\text { symbols, into, concepts and data relevant to their } \\
\text { fields and who also create their own values } \\
\text { depending on their profound expertise. They are } \\
\text { in general the directing managers of middle or } \\
\text { senior management along with the professionals. }\end{array}$ & & \\
\hline
\end{tabular}

Second: Dimensions of Knowledge Workers

Researchers differ in identifying the dimensions of knowledge workers due to the differences in their intellectual and philosophical views and also due to the requirements of the environment surrounding their organizations which push them to adopt certain types of models. Thus in conducting the current paper, and after revising literatures of Knowledge Workers where many different dimensions were dealt with, the researcher chose to also adopt the dimensions upon which former researchers have agreed upon and that as follows:

1. Intellectual Capabilities: These are the results of mental processes and purposeful activities that require conclusive knowledge about the nature of external phenomena an individual is deemed to face [5]. Those results enable the individual to do something, whether mental in nature or physical, and whether being the outcome of gained or inborn capabilities (driven by instinct), so he/she becomes enabled to skillfully and successfully deal with situations [6]. Accordingly, those capabilities are but a means to employ personal experience, skills and creativity in dealing with knowledge and data, making knowledge workers more responsive and more aware of the surrounding environment and its alternations, in addition to enabling them to seize more opportunities, making more threats ineffective and finally enriching them towards building more futuristic visions as they become fully ready for the future through widening their horizons of thinking so they become more committed to strategic orientations of their organizations [7] .

2. Challenge and Achievement: Refers to expecting current situations to change for the better in the future despite all obstacles and difficulties and that depending on the cognitive powers and analytical skills of knowledge workers [8] . It also indicates their level of readiness for facing hard situations, challenging weaknesses in plans and strategies and concurring them [9]. as well as the ability to refresh their knowledge and their abilities to adapt to complex missions of various environments of works [10]. So knowledge workers, in the light of this dimension (of Challenge and Achievement), employ their precious skills and knowledge developed through experience in performing works and solving perplex and unfamiliar problems they face in environments of relational resources and accumulated knowledge [11] .

3. Individual Growth: Knowledge workers achieve creativity and add extra value for the organizations they work for through their knowledge which is personal in nature as well as through their desire to gain individual learning/education (i.e. to learn by their own) which enables them to adapt to the dynamic changes and complicated environments of work [12].Those achievements ensure they achieve job titles like (senior management and middle management directors and professionals). The achievements also empower their capabilities to better understand works, data, concepts and codes involved in the midst of uncertainty and the climate of information shortages, thus enhancing organizational creativities [4]. That is usually achieved through knowledge workers' self-dependence as they become totally independent since the intellectual work requires that the individual takes responsibility for the actions and works to be performed, that is why a knowledge worker is to be held accountable for his/her performance [13].

4. Recognition: It means achieving works and duties assigned in a way through which each individual (knowledge worker) reaches the desired level of goals related to many factors such as cost, quality, and creativity [14]. This recognition is acknowledged by senior leadership of the organization and also by coworkers/colleagues due to the unique characteristics of knowledge workers that distinguish them from others in the organization and in society compared to traditional workers [15], since they (knowledge workers) appear to have the essential knowledge needed and are often the only persons enjoying such knowledge. The recognition is also due to the fruitful employment of ideas (by knowledge workers) in the fields of their specialties, as well as the full and effecting investment of knowledge [16].

\section{The Concept of Strategic Capabilities}

Strategic capabilities arise from the intricate interaction between tangible and intangible resources which enable the organization to create and take advantage of opportunities in the external environment in order to enhance and develop its features and characteristics. Thus, the strategic capabilities represent the energy/power of the organization fully integrated in designin order to reach the desired status [17] Accordingly, organizations differ quantitatively, qualitatively and in terms of timeframes in their levels of strategic capabilities acquired, depending on the availability of tangible and intangible resources (being material in nature, financial, and/or related to human resources and the data available in addition to the time factor). That is why researchers have been in disagreement with one another in respect to defining the concept of strategic capabilities in a definitive way due to their visions, philosophies and mental orientations and also according to their approaches in 


\section{International Journal of Science and Research (IJSR) \\ ISSN (Online): 2319-7064}

Index Copernicus Value (2016): 79.57 | Impact Factor (2015): 6.391

defining strategic capabilities. Table (3) displays strategic capabilities definitions in the light of different approaches by different researchers arranged chronologically.

Table 3: Views of some writers on the concept of strategic capabilities

\begin{tabular}{|c|c|c|}
\hline Definition & $\begin{array}{c}\text { Researcher } \\
\text { \& Year }\end{array}$ & Ref \\
\hline $\begin{array}{c}\text { A complicated and hard-to-imitate resource that } \\
\text { achieves sustainable characteristics/features for } \\
\text { organizations. }\end{array}$ & {$[18]$} & \\
\hline $\begin{array}{c}\text { Complicated bundles of skills and accumulated } \\
\text { knowledge that enable the organization to } \\
\text { organize its assets and activities in order to } \\
\text { create value and maintain its competitive } \\
\text { characteristic. }\end{array}$ & {$[19]$} & \\
\hline $\begin{array}{c}\text { That ability which enables the organization to } \\
\text { devise and carry out strategies capable of } \\
\text { creating sustainable competition. }\end{array}$ & {$[20]$} & \\
\hline $\begin{array}{c}\text { The ability to invest in the internal and external } \\
\text { resources of the organization, reorganizing them } \\
\text { in a way that ensures reaching the goals desired. }\end{array}$ & {$[21]$} & \\
\hline
\end{tabular}

Second: Dimensions of Strategic Capabilities

After reviewing relevant literatures (of strategic capabilities), the researcher chose to adopt the [22] ,model which appears to be in harmony with the topic of the current paper so that to represent a philosophical and practical frame that could be used as a reference to display the dimensions of the strategic capabilities and which includes three main dimensions (the technical knowledge to create value, the capacity to acquire and generate resources and management techniques).
1. Technical Knowledge to Create Value: It is regarded as the most vital and sustainable resource necessary to achieve the competitive characteristic as well as the prominent factor in the success and continuity of organizations [23] It also represents a social structure in which the organization employs its elements to achieve its goals [24].

2. Capacity to Acquire and Generate Resources: Is a number of processes and activities used to acquire unique resources which include all the assets an organization has whether being tangible resources represented by material assets which could be seen and measured like production equipment, storage stuff and facilities or the intangible resources represented by the non-material assets that the directors and employees develop [25].

3. Management Techniques: Methods and solutions used by the workers of the organization to deal with problems and situations that they face which differ in seriousness (severity) and the fluctuating nature. Those techniques are also represented by known tools of works used to help in sharing data and information like: software programs, inventions, processes, databases [26] electronic devices and advanced methods pertinent to generate knowledge through various ways [27].

\section{Research Methodology}

\section{Displaying Results of Knowledge Workers Dimensions:}

Table (10) below shows values of arithmetic mean, standard deviation, coefficient of variation, relative importance as well as relative frequencies for all dimensions of knowledge workers variable.

Table 10: shows the results of answers of research samplings concerning dimensions of knowledge Workers Variable (N=97)

\begin{tabular}{|c|c|c|c|c|c|c|c|c|c|c|c|c|c|c|}
\hline \multirow{3}{*}{$\begin{array}{c}\text { coefficient } \\
\text { of } \\
\text { variation }\end{array}$} & \multirow{3}{*}{$\begin{array}{c}\text { Relative } \\
\text { Importance }\end{array}$} & \multirow{3}{*}{$\begin{array}{r}\text { Standard } \\
\text { Deviation }\end{array}$} & \multirow{3}{*}{$\begin{array}{c}\text { Arithmetic } \\
\text { Mean }\end{array}$} & \multicolumn{10}{|c|}{ Measurement of Answer } & \\
\hline & & & & \multicolumn{2}{|c|}{$\begin{array}{l}\text { I absolutely } \\
\text { disagree }\end{array}$} & \multicolumn{2}{|c|}{ I disagree } & \multicolumn{2}{|c|}{ I'm not sure } & \multicolumn{2}{|c|}{ I agree } & \multicolumn{2}{|c|}{$\begin{array}{c}\text { I absolutely } \\
\text { agree }\end{array}$} & \\
\hline & & & & $\%$ & Ref. & $\%$ & Ref. & $\%$ & Ref. & $\%$ & Ref. & $\%$ & Ref. & \\
\hline $11 \%$ & $83 \%$ & 0.441 & 4.15 & 0 & 0 & 0 & 0 & 3.1 & 3 & 78.4 & 76 & 18.6 & 18 & $\mathrm{q} 1$ \\
\hline $12 \%$ & $83 \%$ & 0.513 & 4.13 & 0 & 0 & 0 & 0 & 7.2 & 7 & 72.2 & 70 & 20.6 & 20 & $\mathrm{q} 2$ \\
\hline $17 \%$ & $79 \%$ & 0.681 & 3.93 & 0 & 0 & 3.1 & 3 & 17.5 & 17 & 62.9 & 61 & 16.5 & 16 & $\mathrm{q} 3$ \\
\hline $18 \%$ & $80 \%$ & 0.707 & 4.00 & 1 & 1 & 0 & 0 & 18.6 & 18 & 58.8 & 57 & 21.6 & 21 & $\mathrm{q} 4$ \\
\hline $20 \%$ & $79 \%$ & 0.783 & 3.97 & 1 & 1 & 1 & 1 & 22.7 & 22 & 50.5 & 49 & 24.7 & 24 & $\mathrm{q} 5$ \\
\hline $11 \%$ & $81 \%$ & 0.43 & 4.04 & \multicolumn{11}{|c|}{ Intellectual Capabilities } \\
\hline $19 \%$ & $79 \%$ & 0.739 & 3.93 & 0 & 0 & 6.2 & 6 & 12.4 & 12 & 63.9 & 62 & 17.5 & 17 & q6 \\
\hline $16 \%$ & $80 \%$ & 0.645 & 4.02 & 0 & 0 & 3.1 & 3 & 10.3 & 10 & 68 & 66 & 18.6 & 18 & $\mathrm{q} 7$ \\
\hline $17 \%$ & $79 \%$ & 0.683 & 3.95 & 0 & 0 & 3.1 & 3 & 16.5 & 16 & 62.9 & 61 & 17.5 & 17 & $\mathrm{q} 8$ \\
\hline $20 \%$ & $77 \%$ & 0.767 & 3.78 & 0 & 0 & 7.2 & 7 & 20.6 & 20 & 58.8 & 57 & 13.4 & 13 & q9 \\
\hline $33 \%$ & $58 \%$ & 0.975 & 2.92 & 5.2 & 5 & 27.7 & 24 & 29.9 & 29 & 37.1 & 36 & 3.1 & 3 & q10* \\
\hline $12 \%$ & $74 \%$ & 0.429 & 3.72 & \multicolumn{11}{|c|}{ Challenge and Achievement } \\
\hline $25 \%$ & $73 \%$ & 0.892 & 3.64 & 1 & 1 & 13.4 & 13 & 17.5 & 17 & 56.7 & 55 & 11.3 & 11 & $\mathrm{q} 11$ \\
\hline $20 \%$ & $79 \%$ & 0.789 & 3.96 & 0 & 0 & 6.2 & 6 & 14.4 & 14 & 56.7 & 55 & 22.7 & 22 & $\mathrm{q} 12$ \\
\hline $18 \%$ & $80 \%$ & 0.722 & 4.00 & 0 & 0 & 3.1 & 3 & 16.5 & 16 & 57.7 & 56 & 22.7 & 22 & q13 \\
\hline $29 \%$ & $70 \%$ & 1.012 & 3.49 & 3.1 & 3 & 15.5 & 15 & 23.7 & 23 & 44.3 & 43 & 13.4 & 13 & $\mathrm{q} 14$ \\
\hline $32 \%$ & $59 \%$ & 0.946 & 2.96 & 5.2 & 5 & 22.7 & 22 & 39.2 & 38 & 28.9 & 28 & 4.1 & 4 & $\mathrm{q} 15^{*}$ \\
\hline $15 \%$ & $72 \%$ & 0.547 & 3.61 & \multicolumn{11}{|c|}{ Individual Growth } \\
\hline $17 \%$ & $82 \%$ & 0.696 & 4.12 & 0 & 0 & 3.1 & 3 & 9.3 & 9 & 59.8 & 58 & 27.8 & 27 & q16 \\
\hline $18 \%$ & $83 \%$ & 0.759 & 4.13 & 0 & 0 & 5.2 & 5 & 7.2 & 7 & 56.7 & 55 & 30.9 & 30 & q17 \\
\hline $22 \%$ & $76 \%$ & 0.846 & 3.81 & 2.1 & 2 & 6.2 & 6 & 15.5 & 15 & 60.8 & 59 & 15.5 & 15 & $\mathrm{q} 18$ \\
\hline $20 \%$ & $74 \%$ & 0.735 & 3.71 & 1 & 1 & 4.1 & 4 & 2.8 & 26 & 58.8 & 57 & 9.3 & 9 & q19 \\
\hline $18 \%$ & $87 \%$ & 0.787 & 4.33 & 1 & 1 & 2.1 & 2 & 7.2 & 7 & 42.3 & 41 & 47.4 & 46 & $\mathrm{q} 20$ \\
\hline $15 \%$ & $80 \%$ & 0.597 & 4.02 & \multicolumn{11}{|c|}{ Recognition } \\
\hline
\end{tabular}

*reversed question 


\section{International Journal of Science and Research (IJSR) \\ ISSN (Online): 2319-7064}

Index Copernicus Value (2016): 79.57 | Impact Factor (2015): 6.391

It is obvious from table (10) that the first dimension of the Knowledge Workers variable (Intellectual Capabilities) has achieved "available" with an arithmetic mean of (4.04), and thus ranked first among the dimensions of the main variable of knowledge workers with a high coherence across the answers of the questionnaire sampling since both the standard deviation and the coefficient of variation were $(0.430,11 \%)$ respectively, whereas the total relative importance of this dimension was $(81 \%)$, noting that this dimension was measured by virtue of (1-5) of the questionnaire points. The first point (professors are able to understand, deal with and use specialized data) achieved an arithmetic mean of (4.15) with high coherence along the answers of the questionnaire due to a standard deviation and a coefficient of variation of $(0.441,11 \%)$ respectively which also seemed to be relatively interesting to the professors sought. While the lowest value was achieved by the third point (Professors take part in enhancing performance through strategic thinking) via an arithmetic mean of (3.93) but with the highest coherence across the answers achieving a standard deviation and a coefficient of variation of $(0.681,17 \%)$ respectively and with a relative importance of $(79 \%)$

The second dimension (Challenge and Achievement) achieved "available" value with an overall arithmetic mean of (3.72) and hence came third among the dimensions of the main variable (knowledge workers) with a high coherence in answers asked. Both the standard deviation and the coefficient of variation were $(4.0429,12 \%)$ respectively with a relative importance of $(74 \%)$. The dimension was measured through points (6-10) of the questionnaire form as point (7) which states (professors use their intellectual skills in facing work obstacles that require challenge). The arithmetic mean was (4.02) with high coherence in sampling's answers via a standard deviation and a coefficient of variation of $(0.645,16 \%)$ respectively. The relative importance was $(80 \%)$. However, the lowest value achieved related to point (10) which was reversely coined (professor avoid works that require self-challenges) with an "about average available" value with an arithmetic mean of (2.92) which was lower than the hypothetical mean set by the research (3) and with a standard deviation and a coefficient of variation of $(0.975,33 \%)$ respectively and a relative importance of $(58 \%)$

Third dimension (individual growth) achieved an "available" value with an arithmetic mean of (3.61) so it ranked fourth among the dimensions of the main variable of knowledge workers. The coherence in answers was high since the standard deviation and the coefficient of variation were $(0.547,15 \%)$ respectively and with a relative importance of (72\%). This dimension was measured through points (11-15) of the questionnaire form. Point (13) that states (professors develop new ideas of work through their individual capabilities) achieved an "available" value with an arithmetic mean of (4.00) and with a high coherence through a standard deviation and a coefficient of variation of $(0.772,18 \%)$ respectively. The relative importance shown by the researched sampling was $(80 \%)$. The lowest value was achieved by point (15) that states (professors easily back off in the face of cases of renewal and development that are disagreed upon by relevant authorities) with an "about average available" value with an arithmetic mean of (2.96) but which was below the hypothetical mean set by the research (3). Its standard deviation and coefficient of variation were $(0.946,32 \%)$ respectively and with a relative importance of $(59 \%)$.

The fourth dimension of the knowledge workers variable(recognition) achieved an "available" value with an overall arithmetic mean of (4.02), thus ranking second among the dimensions of the main variable (knowledge Workers) with a high coherence across the answers of the questionnaire form. Its standard deviation and the coefficient of variation were $(0.597,15 \%)$ respectively and the relative importance was $(80 \%)$. This dimension was measured depending on points (16-20) of the questionnaire form of which point (20) (Faculty professors enjoy capabilities distinguishing them from other workers) achieving a "very available" value with a standard deviation and a coefficient of variation of $(0.787,18 \%)$ respectively, and a relative importance of $(87 \%)$. The lowest value was related to point (19) stating (Professors take part in enhancing performance through strategic thinking) with an "available" arithmetic mean of (3.71) that showed high coherence and agreements in answers. Its standard deviation and coefficient of variation were $(0.735,20 \%)$ respectively and its relative importance was $(74 \%)$.

The professors of the faculties of Salahaddin University of Erbil contribute to the achievements of their faculties' objectives in particular and the objectives of the university in general through the acquisition of their capabilities and as a result of their commitment to their duties and the missions assigned in addition to their realization of the values founded on the culture of the faculties to which they belong. Results are indicative of the fact that the Salahaddin University of Erbil has a teaching staff capable of performing duties and processes needed to test the scientific environment of the university as well as to observe the performance of other universities. Moreover, they appear to be ready to face both scientific and administrative challenges, beating difficulties and successfully carrying out all missions and duties assigned to them more often without the need for directions, so that they achieve high levels of scientific and intellectual developments in their fields independently and out of their free wills. They also show a real desire in self-education and learning that goes in harmony with their qualifications and scientific position which in turn refers to the reality of the unique characteristics and traits.

\section{- Displaying the results of strategic capabilities dimensions:}

Table (11) below shows values of arithmetic mean, standard deviation, coefficient of variation, relative importance and relative frequencies on the gross level of dimensions of the strategic capabilities. 


\section{International Journal of Science and Research (IJSR) \\ ISSN (Online): 2319-7064}

Index Copernicus Value (2016): 79.57 | Impact Factor (2015): 6.391

Table 11: results of the questionnaire samplings regarding the dimensions of the strategic capabilities

\begin{tabular}{|c|c|c|c|c|c|c|c|c|c|c|c|c|c|c|}
\hline \multirow{3}{*}{$\begin{array}{l}\text { coefficient } \\
\text { of variation }\end{array}$} & \multirow{3}{*}{$\begin{array}{l}\text { Relative } \\
\text { Importance }\end{array}$} & \multirow{3}{*}{$\begin{array}{l}\text { Standard } \\
\text { Deviation }\end{array}$} & \multirow{3}{*}{$\begin{array}{c}\text { Arithmetic } \\
\text { Mean }\end{array}$} & \multicolumn{10}{|c|}{ Measurement of answer } & \\
\hline & & & & \multicolumn{2}{|c|}{$\begin{array}{c}\text { I absolutely } \\
\text { disagree }\end{array}$} & \multicolumn{2}{|c|}{ I disagree } & \multicolumn{2}{|c|}{ I'm not sure } & \multicolumn{2}{|c|}{ I agree } & \multicolumn{2}{|c|}{$\begin{array}{c}\text { I absolutely } \\
\text { agree }\end{array}$} & \\
\hline & & & & \begin{tabular}{|l|}
$\%$ \\
\end{tabular} & Ref. & $\%$ & Ref. & $\%$ & Ref. & $\%$ & Ref. & $\%$ & Ref. & \\
\hline $16 \%$ & $81 \%$ & 0.667 & 4.05 & 0 & 0 & 3.1 & 3 & 10.3 & 10 & 64.9 & 63 & 21.6 & 21 & $\mathrm{q} 21$ \\
\hline $20 \%$ & $78 \%$ & 0.696 & 3.88 & 0 & 0 & 4.1 & 4 & 18.6 & 18 & 62.9 & 61 & 14.4 & 14 & $\mathrm{q} 22$ \\
\hline $18 \%$ & $84 \%$ & 0.736 & 4.18 & 0 & 0 & 3.1 & 3 & 10.3 & 10 & 52.6 & 51 & 34 & 33 & $\mathrm{q} 23$ \\
\hline $17 \%$ & $80 \%$ & 0.685 & 4.01 & 0 & 0 & 4.1 & 4 & 10.3 & 10 & 66 & 64 & 19.6 & 19 & q24 \\
\hline $25 \%$ & $84 \%$ & 1.031 & 4.18 & 2.1 & 2 & 8.2 & 8 & 8.2 & 8 & 33 & 32 & 48.5 & 47 & $\mathrm{q} 25$ \\
\hline $15 \%$ & $81 \%$ & 0.617 & 4.06 & \multicolumn{11}{|c|}{ Technical Knowledge to Create Value } \\
\hline $14 \%$ & $82 \%$ & 0.568 & 4.10 & 0 & 0 & 2.1 & 2 & 5.2 & 5 & 73.2 & 71 & 19.6 & 19 & $\mathrm{q} 26$ \\
\hline $24 \%$ & $75 \%$ & 0.905 & 3.74 & 1 & 1 & 10.3 & 10 & 19.6 & 19 & 51.5 & 50 & 17.5 & 17 & $\mathrm{q} 27$ \\
\hline $30 \%$ & $64 \%$ & 0.958 & 3.18 & 7.2 & 7 & 13.4 & 13 & 37.1 & 36 & 39.2 & 38 & 3.1 & 3 & $\mathrm{q} 28$ \\
\hline $24 \%$ & $77 \%$ & 0.939 & 3.85 & 1 & 1 & 9.3 & 9 & 18.6 & 18 & 46.4 & 45 & 24.7 & 24 & $\mathrm{q} 29$ \\
\hline $38 \%$ & $64 \%$ & 1.239 & 3.20 & 20.6 & 20 & 20.6 & 20 & 21.6 & 21 & 32 & 31 & 5.2 & 5 & $\mathrm{q} 30^{*}$ \\
\hline $15 \%$ & $\mathbf{7 2} \%$ & 0.557 & 3.61 & \multicolumn{11}{|c|}{ Capacity to Acquire and Generate Resources } \\
\hline $19 \%$ & $77 \%$ & 0.741 & 3.85 & 0 & 0 & 7.2 & 7 & 14 & 14.4 & 64.9 & 63 & 13.4 & 13 & $\mathrm{q} 31$ \\
\hline $27 \%$ & $70 \%$ & 0.948 & 3.52 & 13.4 & 13 & 19.4 & 19 & 43.3 & 42 & 20.6 & 20 & 3.1 & 3 & q32 \\
\hline $36 \%$ & $56 \%$ & 1.017 & 2.80 & \begin{tabular}{|l|}
1 \\
\end{tabular} & 1 & 16.5 & 16 & 24.7 & 24 & 45.4 & 44 & 12.4 & 12 & $\mathrm{q} 33$ \\
\hline $25 \%$ & $74 \%$ & 0.906 & 3.69 & 0 & 0 & 14.4 & 14 & 17.5 & 17 & 52.6 & 51 & 15.5 & 15 & q34 \\
\hline $34 \%$ & $64 \%$ & 1.096 & 3.20 & 13.4 & 13 & 27.8 & 27 & 26.8 & 26 & 28.9 & 28 & 3.1 & 3 & $\mathrm{q} 35^{*}$ \\
\hline $16 \%$ & $68 \%$ & 0.558 & 3.41 & \multicolumn{11}{|c|}{ Management Techniques } \\
\hline
\end{tabular}

*reversed question

According to table (11), the first dimension of the strategic capabilities variable (technical knowledge to create value) achieved an "available" value with an arithmetic mean of (4.06) and thus ranked first among other dimensions of the main variable of strategic capabilities with a high coherence in regards to the answers of the questionnaire form. Its standard deviation and coefficient of variation were $(0.617$, $15 \%)$ respectively, while the relative importance for this dimension was $(81 \%)$. The dimension was measured depending on points (20-25) of the questionnaire form, of which point (23) (A faculty depends on knowledge to do whatever deemed to find value for students) achieved an "available" arithmetic mean of (4.18) with a high coherence across the answers of the questionnaire. Its standard deviation and coefficient of variation turn out to be $(0.736$, $18 \%)$ respectively with the relative importance of $(84 \%)$. Likewise, point (25) of the questionnaire (the faculty supports its teaching staff due to their intellectual and knowledge contributions) achieved an "available" arithmetic mean of (4.81). The standard deviation, coefficient of variation and relative importance were (1.031, $25 \%$ and $84 \%$ ) respectively. The lowest value was related to point (22) (A faculty has the knowledge needed to adapt to the requirements of the external environment) with an "available" arithmetic mean of (3.88) with a high coherence in regards to the answers of the questionnaire. Its standard deviation and coefficient of variation were $(0.696,20 \%)$, a relative importance of $(78 \%)$.

As to the second dimension (the capacity to acquire and generate recourse) it achieved an "available" value with an overall arithmetic mean of (3.61), thus ranking second among the dimensions of the main variable of the strategic capabilities. The coherence in answering the questionnaire here was high as the standard deviation as well as the coefficient of variation were $(0.557,15 \%)$ respectively, the relative importance $(72 \%)$. This dimension was measured through points (25-30) of the questionnaire form, of which point (26) which states that (the faculty believes that variation of recourses is the base for building its strategic capabilities) achieved an "available" value with an arithmetic mean of (4.10) and with high coherence in relation to the answers of the questionnaire. The standard deviation and the coefficient of variation were $(0.568,14 \%)$ respectively and with a relative importance of $(82 \%)$. The lowest value achieve related to point (28) which states (The faculty uses moral and material incentives to maintain its human recourses) with an "above average" value with an arithmetic mean of (3.18) but it was above the hypothetical mean set by the research. Coherence in answers was obvious. The standard deviation and the coefficient of variation were $(0.958,30 \%)$ respectively and with a relative importance of (64\%). Moreover, point (30) which was reversely coined as (What the faculty has as recourses is not enough to raise the quality of its performance) achieved an "above average" value with an arithmetic mean of (3.20). Answers showed incoherence in regard to this point where standard deviation was (1.239), coefficient of variation $(38 \%)$ and a relative importance of $(68 \%)$.

Management techniques, as a dimension appeared "available" with an arithmetic mean of (3.41) and thus ranked third among the dimensions of the main strategic capabilities variable. Its relevant answers were highly coherent in nature. Its standard deviation and coefficient of variation were $(0.558,16 \%)$ respectively, its relative importance $(68 \%)$. The dimension was measured relying on points (30-35) of the points included in the questionnaire, of which point (31) (The faculty believes that proficiency is complementary to workers in building its strategic capabilities) achieved an arithmetic mean of (3.85) with a good coherence in terms of the answers given in response to the questionnaire. Its standard deviation and coefficient of variation were $(0.741,19 \%)$ respectively and with a relative importance of $(77 \%)$.

The lowest value related to point (35) that states (The proficiency the faculty has doesn't meet its need to

\section{Volume 6 Issue 12, December 2017}




\section{International Journal of Science and Research (IJSR) \\ ISSN (Online): 2319-7064}

Index Copernicus Value (2016): 79.57 | Impact Factor (2015): 6.391

achieve creativity) with an "above average" value of an arithmetic mean of (2.80) i.e. less than the hypothesized mean since this question was reversed which, in turn, weakened the coherence of relevant answers. Its standard deviation and coefficient of variation were $(1.017,36 \%)$ with a relative importance of $(56 \%)$. Former results indicate that Salahaddin University in all its faculties has a reservoir of information, data and techniques supported by scientific methods directed to and investing in creating and building high levels of creativities as well as enhancing curriculums in a way that ensures solidifying the position of the university. This is achieved through the university adopting a series of activities aimed at gaining its resources (material, financial, human, data and time), in addition to determining the means by which the university would be able to sustain those resources within a practical framework appropriate with the reality of its faculties as well as its current and future requirements. Likewise, the university has access to tactical information and methods in use with the objective being to organize and develop the various incoming recourses that are to be dealt with in a smart way that ensures achievement of the goals of the university.

\section{References}

[1] Davenport, T. H., (2005), Thinking For a Living: How To Get Better Performance and Results From Knowledge Workers ,Boston: Harvard Business School Press.

[2] Noe, Raymond A ,(2006) , Human Resource Management: Gaining A Competitive Advantage, 5th Edition, McGraw-Hill Irwin, New York.

[3] Wu. J, (2008), On the Management Based on Characteristics of Knowledge Workers , Modern Applied Science, Vol. 2, No. 2,.

[4] Wang, Yumei\& Zhu, Zhen \&Cong,Qing , (2008), An Analysis on the Knowledge Workers'Turnover: A Psychological Contract Perspective International Journal of Business and Management, Vol. 3, No. 3,PP.62-65.

[5] Al_Zaidi, Qais Ibrahim Hussein, (2000), the style of strategic thinking of the leadership levels in Iraqi public administration organizations and its impact on their attitudes toward strategic change, the introduction of knowledge, master's degree in public administration, College of Management and Economics _ Baghdad University.

[6] Shrap, NidalHamdan Salem, (2007), a study of some mental abilities among Palestinian university students, Master of Psychology, Faculty of Education, Islamic University, Gaza.

[7] Al-Obeidi, AardenHatemKhudair (2010), Information Technology and Strategic Thinking and their Impact on the Strategy of Organizational Innovation, Applied Study in Mustansiriya University Faculties, Department of Business Administration, University of Mustansiriya.

[8] Makki, Latif Ghazi and Hassan, Bara Mohammed (2009), The Hardness of Personality and its Relation to Self-Esteem among Teaching Staff at the University, Journal of Educational and Psychological Research, Baghdad University, No. (31).
[9] Al-Taher, AsmahanMajid, (2012), Knowledge Management,First Edition , Dar Wael Publishing and Distribution, Amman, Jordan.

[10]Zhang, Yue\& Zhan, Hong \& Tang, Tian (2013), The Research on Characteristics of Knowledge Workers and Their Motivating Factors: A Review and Comparison Study, American Journal of Industrial and Business Management .

[11] Kelly. G., Mastroeni. M., Conway. E., Monks. K., Truss. K, Flood.\& Hannon. E,(2011), Combining Diverse Knowledge: Knowledge Workers' Experience of Specialist and Generalist Roles" Emerald Journal, Vol.40, No. 5.

[12]Zhan' Hong \& China' Fujian \&Peng' Lifang\& Ma' Yuanyuan\& Lin' Jianhuang'(2014)'the Research on Characteristics of E_Commerce Enterprises 'Knowledge Workers and their Motivating Factors : A Review and Comparison Study'Australasian Conference on Information Systems'Auckland'New Zealand.

[13]Farkas , Maria Fekete\&Torok , L. Gabor ,(2011), Knowledge Workers, Competencies, Virtuality And Management, Polish Journal Of Managemenet Studies, vol.4,PP.67-77.

[14] Sikyr , M , (2013) , Best Practices in Human Resource Management: The Source of Excellent Performance and Sustained Competitiveness" Central European Business Review Research Papers , Vol. 2, No. 1 .

[15]Cheng, Wen\& Zhang, Guoliang , 2008, Self-motivator Factors of Senior Knowledge Workers" IEEE .

[16] Mladkova, Ludmila,( 2011), Management of Knowledge Workers" Emerald Group Publishing Limited, International Journal of Productivity and Performance Management, Vol. 54, No. 6.

[17] Hitt, Michael A.; Freeman, R. Edward \& Harrison, Jeffrey S., (2001), "Strategic management", South Western, Collage Publication, UK. p.107.

[18] Mavondo , F.T \& Lim , S.K , (2000), The structure of strategic capabilities, implications for organisational agility and superior performance: a conceptual framework, Department of Marketing, Monash University, Melbourne, Australia.

[19] MohantaG.C ,Kannan V. , Thooyamani K.P. ,(2006), Strategies for Improving productivity of knowledge workers - An overview, the Brisbane Institute of strengths based practice Inc in collaboration with sanghamitra Andhra Pradesh - India , 10-12 november , Hyderabad, India.

[20]Desarbo , Wayne \&Benedtto , Anthony \& Song , Michael \&Sinha , Indrajit ( 2005), Revisiting The and Snow Strategic Framework:Uncovering Interrelationships Between Strategic Types, Capabilities , Environmental Uncertainty, and Firm Performance ,Strategic Management Journal ,Vol . 26.

[21]Armstrong , Michael , (2008) , Strategic Human Resource Management, A guide To Action , Fourth edition, Printed and bound in India by Replika Press Pvt Ltd..

[22] Chen, Lu-Jui\&Chen , Chun-Chung\& Lee, WenRuey,(2008) , BStrategic Capabilities, Innovation Intensity, and Performance of Service Firms , J. Serv. Sci. \& Management. 


\section{International Journal of Science and Research (IJSR) \\ ISSN (Online): 2319-7064}

Index Copernicus Value (2016): 79.57 | Impact Factor (2015): 6.391

[23]Lenz, C. (1980), Strategic Capability: A Concept and Framework for Analysis, Academy of Management Review, Vol. 5, No. 2.

[24] Abdel-Razzaq, Omar Mohamed Subhi, (2009), The Influenceof the Leadership Style in Strategic Capacity Building of the Organization, An Analytical Study of the Opinions of Directors in a Sample of Industrial Organizations in Nineveh Province, Al-Rafidain Development Journal, Mosul University, College of Management and Economics, Vol. 31, No. 93.

[25]Al_Shammari, Mohammed Jabbar and Hadrawi, Hamid Kareem,(2010), Knowledge Management Processes and their Impact on Indicators of the Knowledge Economy, An Analytical Study of the Opinions of a Sample of Digital Institutions, College of Management and Economics, University of Kufa.

[26] Ismail ,AliminIsmadi\& Rose ,RaduanChe\&Uli JJegak\&Abdullah,Haslinda, (2012) ,the Relationship Between Organisational Resources Capabilities , Capabilities , Systems and Competitive Advantage ,Asian Academy of Management Journal, Vol. 17, No. 1.

[27] Khalaf, AminaIbraheem, (2014), Measurement of intellectual assets and their evaluation using Balanced Scorecard, Applied Research in Diyala General Company for Electrical Industries, Accounting and Administrative Accounting, Higher Institute of Accounting and Financial Studies, Baghdad University.

[28] Nayef, BasemFaysalAbd (2012), Building an Educated Organization in the Framework of Integrating Knowledge Management Processes and Fundamental Capacities, An Analytical Study of a Sample of Employees in the Ministry of Science and Technology, $\mathrm{PhD}$ in Public Administration, College of Management and Economics, University of Baghdad.

\section{Author Profile}

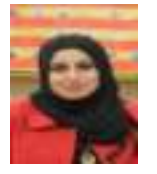

Hadeel Kadhim Saeed, B. Sc. in Public Administration Baghad University College of Administration and Economy 1996. M. Sc. in Public Administration Baghdad University College of Administration and Economy2001 .PH.D in Public Administration Baghdad University College of Administration and Economy 2007.Teaching in the Department of public administration - College of Economy and Administration since 2007. Published a number of researches in academic journals .Give lectures to High students' in public administration .Supervision of the PHD dissertation and Masters and Higher Diploma thesis. Preparation of training programs and lectures to the trainees in the advisory office of the Economy and Administration College and government departments. Providing consulting and lecturing in government departments and civil society organizations

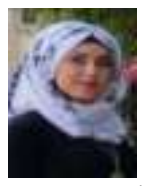

Baraa Shawqi Al-Ani, studied public administration in Al_Anbar University College of Administration and Economy, And graduated in 2014. Studied master's, Department of Public Administration, College of Administration and Economic, University of Baghdad in 2015

Volume 6 Issue 12, December 2017 www.ijsr.net 